\title{
La doctrina de la libertad en el pensamiento ácrata: de Manuel González Prada y Manuel y Delín Lévano a Avram Noam Chomsky
}

\author{
Leonel Patricio Silva Montellanos \\ Universidad: Universidad Nacional Mayor de San Marcos \\ leonel.silva@unmsm.edu.pe
}

\section{Resumen}

Analiza, bajo la metodología analítico-hermenéutico, los aportes de Manuel González Prada y Manuel y Delfín Lévano, exponentes del pensamiento libertario peruano de inicios del siglo XX y los confronta con los de Noam Chomsky. Propone que el discurso ácrata se legitima como crítica radical de los sistemas políticos imperantes en occidente (Monarquía, Dictadura, República democrática) desde mediados del siglo XIX, luego de constatarse las carencias de estos sistemas de gobierno para resolver los problemas económicos y sociales. El discurso ácrata surge como la confluencia del liberalismo y el socialismo, y como corpus teórico se halla vigente y puede ser considerado como filosofía o cosmovisión con implicancias ontológicas, axiológicas, éticas, gnoseológicas.

Palabras clave: Acracia, Anarquía, Democracia, Ética, Filosofía, Libertad

\begin{abstract}
Analyses, under the analytical methodology-hermeneutic, the contributions of Manuel González Prada and Manuel and Delfin Lévano, exponents of the Peruvian libertarian thought of the beginnings of the twentieth century and confronts them with those of Noam Chomsky. He proposes that the anarchist discourse is legitimized as a radical critique of the prevailing political systems in the West (monarchy, dictatorship, Democratic Republic) since the mid-nineteenth century, after the shortcomings of these systems of government were found to Solve economic and social problems. The discourse anarchist emerges as the confluence of liberalism and socialism, and as a corpus theoretical is in force and can be considered as a philosophy or worldview with ontological implications, axiological, ethics, Gnoseológicas.
\end{abstract}

Keywords: Acracy, Anarchy, Democracy, Ethics, Philosophy, Freedom 


\section{La doctrina de la libertad en el pensamiento ácrata: de Manuel González Prada y Manuel y Delíín Lévano a Avram Noam Chomsky ${ }^{1}$}

\section{La doctrina de la libertad en el pensamiento de Manuel González Prada}

Manuel González Prada, luego de su paso por el nacionalismo y la creencia republicana define a su obra en el sentido positivo de la acracia, la revolución genuina de tierra y libertad. Más esta revolución, no será como las anteriores, producto de la verticalidad jerarquizante: la acracia habrá de darse entre seres humanos libres, iguales y solidarios. Este sería su aporte original. En la acracia no reina el espíritu de milicia ni de política; no hay propiedad ni trabajo que enajenar. Es un acuerdo social basado en principios éticos sólidos y no en liderazgos ni oportunismos.

Lo problemático de este modelo o proyecto social es que apela a la conciencia y a los escrúpulos de las personas; por tanto, no acepta concesiones motivadas por el temor o el uso de la fuerza. Esta dificultad precisamente constituye la riqueza de la acracia como filosofía, pues se espera, en tanto doctrina, una validación práctica hecha realidad por mejores seres humanos — esto es, mejores personas-; que asuman la vida y complejidad con la entereza de ser responsables y altruistas, formados y capacitados para la crítica y el análisis.

Si observamos la historia de la civilización occidental, en la antigua Grecia y Roma, en el Medievo europeo; primero bárbaro, luego cristiano, siempre algo falló. Cuando la sociedad estaba lista para asumir colectivamente sus responsabilidades, aparecía un grupo de intrigantes, hábiles en la negociación y el manejo del poder y se hacían del dominio de la situación. Luego vinieron antecedentes como el Renacimiento, la Modernidad, la Reforma, la Ilustración, las revoluciones antimonárquicas y liberales, etc., pero el panorama siguió siendo el mismo.

1 Se menciona el nombre completo del lingüista norteamericano: Avram Noam Chomsky, como señal de respeto a su origen judío; en tanto él mismo firma como Noam Chomsky, decidí corregir y evitar desconciertos innecesarios. Me parece pertinente dejar constancia de esta aclaración. 
Este examen de las diversas circunstancias históricas reafirmó la postura aristotélica: existen seres que nacen para ejercer el dominio y seres que desde su nacimiento están destinados a ser dominados. Con ello se justificó una teoría de la historia que contemplaba como parte natural de la esencia humana la violencia, la injusticia, el abuso, la prepotencia, la arbitrariedad, etc., relegando al reino de la utopia ${ }^{2}$ toda esperanza de justicia. Había nacido el principio del egoísmo y la amoralidad. Este fue el sustento de las prácticas políticas como el mercantilismo, la industrialización, el colonialismo, el capitalismo, la guerra, etc. Así nos acostumbramos a la civilización del oro y el plomo.

\subsection{Acercamiento teórico al pensamiento de Manuel González Prada}

Nadie espera ya que de un Parlamento nazca la felicidad de los desgraciados ni que de un gobierno llueva el maná para satisfacer el hambre de todos los vientres. La oficina parlamentaria elabora leyes de excepción y establece gabelas que gravan más al que posee menos; la máquina gubernamental no funciona en beneficio de las naciones, sino en provecho de las banderías dominantes. (...) Reconocida la insuficiencia de la política para realizar el bien mayor del individuo, las controversias y luchas sobre formas de gobierno y gobernantes, quedan relegadas a segundo término, mejor dicho desaparecen. Subsiste la cuestión social, la magna cuestión que los proletarios resolverán por el único medio eficaz: la revolución. No esa revolución local que derriba presidentes o zares y convierte una república en monarquía o una autocracia en gobierno representativo; sino la revolución mundial, la que borra fronteras, suprime nacionalidades y llama la humanidad a la posesión y beneficio de la tierra.

(González Prada, 1905/2010)

Manuel González Prada señala la problemática vigente, su escepticismo respecto del modelo democrático parlamentarista, según su argumento, la república basa su existencia en instituciones de legalismo abstracto, profundamente deshumanizadas y al mismo tiempo, basa su eficacia, en el poder del oro y el plomo: el dinero y el uso legal de la violencia y de ser necesario, la instrumentalización de la muerte. Este escepticismo no es patrimonio del notable pensador y poeta peruano.

En el siglo XIX, producto del estudio y confluencia de doctrinas complementarias como el socialismo y el liberalismo, surge el discurso ácrata (Bakunin, 1871/2002), que nuestro paradigmático pensador adhiere. Esto le lleva a una exigencia reafirmante de la crítica cuestionadora de lo establecido. Recordemos que el Perú terminaba de soportar la embestida invasora del ejército chileno, convertido en instrumento de una oligarquía sureña, sirvienta del imperialismo inglés. Esta guerra de conquista mostró el lado más terrible y desolador de la violencia institucionalizada. De ahí, a decepcionarse de instituciones políticas que legitiman la fuerza y la brutalidad y adherir al pensamiento ácrata, hay sólo un paso y Manuel

2 Aquello que no tiene ni tendrá lugar en el mundo objetivo de la historia. 
González Prada, lo dio. Su gesto fue la consecuencia de una auténtica reflexión, entendiendo por esta, el ejercicio cuidadoso de la capacidad racional, enfocada en una dimensión axiológica y ontológica. He aquí un ejemplo de la vinculación entre acracia y filosofía.

Observemos como primer elemento del problema que la acracia es la reacción espontánea de la naturaleza humana, pasada por el tamiz de la razón, ante una situación de arbitrariedad. Segundo, se caracteriza por ser una genuina y legítima rebeldía ante situaciones que no pueden esperar más por su solución. Debe recordarse que, en el Mundo civilizado, siempre hubo lugar consagrado para el ejercicio del poder. A ello podría oponerse, como tercer elemento, que condiciona la necesidad de la crítica, que al menos, en términos morales, siempre hubo justificación para la divergencia, para el derecho a la negación.

\subsection{Contexto cultural del pensamiento de Manuel González Prada}

Los intelectuales sirven de luz; pero no deben hacer de lazarillos, sobre todo en las tremendas crisis sociales donde el brazo ejecuta lo pensado por la cabeza. Verdad, el soplo de rebeldía que remueve hoy a las multitudes, viene de pensadores o solitarios. Así vino siempre. La justicia nace de la sabiduría, que el ignorante no conoce el derecho propio ni el ajeno y cree que en la fuerza se resume toda la ley del universo. Animada por esta creencia, la humanidad suele tener la resignación del bruto: sufre y calla, Más de repente, resuena el eco de una gran palabra, y todos los resignados acuden al verbo salvador, como los insectos van al rayo del sol que penetra en la oscuridad del bosque. (...) Toda revolución arribada tiende a convertirse en gobierno de fuerza, todo revolucionario triunfante degenera en conservador. ¿Qué idea no se degrada en la aplicación? ¿Qué reformador no se desprestigia en el poder? Los hombres (señaladamente los políticos) no dan lo que prometen, ni la realidad de los hechos corresponde a la ilusión de los desheredados. El descredito de una revolución empieza el mismo día de su triunfo; y los deshonradores son sus propios caudillos.

(González Prada, 1905/2010)

Aún con otros rostros y nombres, se asentó una tradición de la inconformidad y la ruptura, la crítica racional. Por ejemplo, la divergencia entre José de San Martín y Simón Bolívar, ambos necesitaban acabar con el poderío militar del virreinato del Perú, para asegurar la independencia de la Argentina y de la Gran Colombia. No fue desinteresada solidaridad independentista la que los trajo al Perú; ambos coincidían en la necesidad de la liberación y, sin embargo, sustentaban enfoques distintos: republicano el caraqueño; y monárquico-constitucionalista el rioplatense. Finalmente, se impuso la doctrina bolivariana.

Es verdad que ambos creían en la necesidad de acabar con el yugo español pero el punto débil, la inconsistencia de sus postulados, radicaba en que su crítica política se detenía en los protocolos y protagonismos; no abordaban el asunto de la libertad con la radicalidad necesaria. Redujeron la liberación a un cambio de banderas, 
de insignias. ${ }^{3}$ Así, una vez más, en la historia, la libertad se redujo a proclama ceremoniosa. Ciertamente, pudo haber republicanos honestos como José Faustino Sánchez Carrión "El solitario de Sayán”, pero fueron la excepción.

Como intelectual ilustrado, González Prada tenía conciencia de las necesidades históricas y sabía que la auténtica libertad radicaba en las propias capacidades del hombre. Cuando luego del desastre de la guerra del Pacífico opta por la acracia, este fue un acto de madurez espiritual, sustentado en la problemática y dificultades respectivas. Se colige que la liberación no es producto de la inmadurez, sino de la responsabilidad.

Luego de constatar la improductividad del sistema republicano, como ácrata convencido, González Prada señala el aporte del rasgo definitivo del discurso libertario: la prioridad del factor social y económico. América Latina, a inicios del siglo XIX, después de la formación de las repúblicas continuaban los contrastes marcados por la desigualdad, la exclusión, la existencia de privilegios y sometimientos. El Perú que conoció Manuel González Prada, a comienzos del siglo XX, era un notable ejemplo de toda esa cultura de arbitraria inmadurez, convivencia, dogmatismos e ignorancias.

Sirva el Perú de la época, con su incipiente desarrollo, con sus notables desigualdades de bastardías y abolengos, como un ejemplo de aquello en que se había convertido el nuevo mundo como consecuencia de la brutalidad del voraz modelo de desarrollo capitalista occidental: ciertamente, la barbarie fue ejecutada contra bolivianos y peruanos, mal organizados, por los soldados chilenos. Pero, como se recordó, esta guerra de conquista ${ }^{4}$ sólo fue hecha para complacer y satisfacer los apetitos del imperialismo inglés. ¿No habían acaso luchado juntos, ambos pueblos, en las batallas de Junín y Ayacucho, para acabar con el yugo español? La burguesía y oligarquía chilenas tuvieron el objetivo claro desde el comienzo. Implementaron un sistema educativo que sirviese a sus intereses. La ideología de la envidia y el odio hacia el otrora poderoso virreinato fue ingresando en la mentalidad del pueblo. Por eso el soldado chileno fue cruel y despiadado.

La herida estaba abierta cuando González Prada, da el giro en su pensamiento. Tuvo la lucidez de percibir que la decadencia y sordidez del modelo capitalista tenía su más grande expresión en la violencia de la guerra. De ahí su escepticismo y su distanciamiento del nacionalismo; el cual no era más que la justificación de nuevas

3 El presidente Ramón Castilla, militar, abolió el tributo indígena (5/7/1854) y la esclavitud de los afrodescendientes (5/12/1854) —durante su mandato en 1849 se inició la inmigración china que operaron como siervos y vieron en las tropas chilenas, en la guerra del Pacífico, a sus libertadores-. (Basadre, 1998).

4 Alrededor de 1830, el ideólogo chileno Diego Portales, teorizaba acerca de la necesaria expansión chilena hacia el norte. Así, se estaba copiando el modelo expansionista estadounidense que arraso con las poblaciones nativas originarias de Norteamérica: (Biblioteca Nacional de Chile, 2016). 
violencias e intolerancias. Se explica así su crítica racional de la situación imperante y el trascendental significado de sus planteamientos.

González Prada habla de revolución, de la revolución ácrata por la tierra y la libertad (Loach, 1995). ${ }^{5}$ A su retorno de Europa observa la realidad peruana desde otra perspectiva, algo que no hubiera logrado hacer de mantener la concepción republicana y nacionalista que en el pasado lo motivó. No es un caso extraño en el contexto del movimiento ácrata mundial: el mismo Mijail Bakunin (1871/2002), ácrata ruso, tuvo formación militar y fue nacionalista eslavista y republicano, antes de abrazar el pensamiento ácrata.

Si se ha admitido al nivel de las abstracciones teóricas que el pensamiento y la actitud libertarias son el resultado de la interacción de los discursos socialistas y liberales, no tiene por qué extrañar que, en el mundo concreto de las prácticas sociales, los pensadores revolucionarios hayan experimentado en su propia vida, similar proceso de evolución y maduración ideológica.

Los hombres que viven insertados en el mundo de la historia participan de procesos económicos y sociales que los condicionan y muchas veces, los determinan. El producto de esa dinámica de las fuerzas sociales es la cultura que queda registrada en determinado tiempo y lugar. Por eso no es de extrañar que brillantes teóricos como Karl Marx y Friedrich Engels (1848), ${ }^{6}$ pese a su genialidad intelectual, se hayan quedado en el camino y no avizoraron las incongruencias de postular un socialismo volcado a la política y a la tradición de la verticalidad y las jerarquías. Esa sobriedad espiritual e intelectual y el consiguiente rigor teórico son otra cualidad de los planteamientos libertarios gonzalezpradianos. Su objetivo no era la refundación de la política o de la república: era el acceder a otra etapa de la historia. La justicia de la sociedad sin clases ni estructuras de dominación.

\subsection{Relevancia del pensamiento de Manuel González Prada}

El caso de González Prada es ejemplar si pensamos en el mundo intelectual de la época. Menos complicado hubiera sido para él, avanzar del lado de la institucionalidad, ponerse del lado de aquellos consagrados por la cultura oficial y los prejuicios y taras que lo rodeaban. Nuestro autor, con conciencia de clase, en tanto trabajador intelectual que se despoja de sus privilegios para asumir un compromiso social con los proletarios, eligió la divergencia, el disentimiento, la crítica de la cultura y del

5 Loach, Ken (cineasta nacido en 1936): Tierra y libertad (Land and freedom) film sobre la revolución española, realizado desde el punto de vista trotskista. Filmado en 1995. El título hace referencia a la consigna libertaria que unió a ácratas y trotskistas frente a los enemigos comunes: el stalinismo y el falangismo. En: http://cine.estamosrodando.com/peliculas/tierra-y-libertad/ ficha-tecnica-ampliada

6 Marx, Karl: (1818-1883), Engels, Friedrich: (1820-1895). Exponentes del socialismo autoritario europeo. 
sistema imperante. Por eso nos ha parecido, a manera de ejemplo histórico que permita explicar nuestra argumentación teórica, partir de sus postulados que son genuina expresión de discurso ácrata.

Cabe recordar que el interés por la obra de este pensador peruano no es en cuanto poeta o crítico literario o testigo del desastre de la guerra; sino su labor como teórico del discurso libertario. Hacemos esto para explicar y plantear, además, la viabilidad de la crítica ácrata: Manuel González Prada, como buen ácrata, era escéptico respecto de los vanguardismos. Como genuino rebelde, no deificaba ni entronizaba a los caudillos o dirigentes. En cumplimiento de imperativos morales, depositaba su confianza en el pueblo, esto es, la humanidad y reconocía el valor de la educación y la ciencia como herramientas de trabajo y progreso.

Iniciar nuestros planteamientos citando a un pensador peruano de la talla de Manuel González Prada, permite clarificar qué entendemos por discurso y filosofía ácrata. Seguidamente, explicaremos los planteamientos de Manuel y Delfín Lévano, quienes a la par de Don Manuel, demostraron con total consistencia y solvencia teórica que la humildad de orígenes no es impedimento para realizar notables contribuciones en el ámbito de la teoría y la propuesta social.

\section{La doctrina de la libertad en el pensamiento de Manuel y Delfín Lévano}

Cuando Manuel y Delfín Lévano iniciaron su labor de difusores de la acracia, aún se tenía presente el recuerdo de la fratricida guerra del Pacífico. ${ }^{7}$ El Perú y América Latina empezaban un proceso de cambios: luego de la liberación de la corona hispánica, el imperialismo inglés había extendido sus dominios y en los siguientes años del siglo XX, no tardaría en entrar en acción el imperialismo norteamericano. En la misma época, estaban vigentes en Europa pensadores libertarios como Anselmo Lorenzo (1913), ${ }^{8}$ fundador de la Confederación Nacional del Trabajo (1910), - anarco-sindicato español que aún subsiste-; pensadores activistas de la envergadura de Piotr Kropotkin (1922), ${ }^{9}$ geógrafo y etólogo ruso, teórico del comunismo ácrata.

La producción teórico-crítica peruana, alcanzo protagonismo mundial, ya en las primeras décadas del siglo XX, se teorizaba aquí en el Perú, sobre la acracia y los fundamentos de la crítica social del sistema político vigente en el mundo occidental y en su periferia cultural latinoamericana. ${ }^{10} \mathrm{La}$ acracia se presentaba como una

7 Interactuaron en las primeras décadas del siglo XX y estaba presente la experiencia de la primera guerra mundial.

8 Lorenzo, Anselmo (1841-1914).

9 Kropotkin, Piotr Alexeievich (1842-1921).

10 Cabe recordar que quienes consiguieron años después, la reducción de la jornada laboral a ocho horas en el Perú, en 1919, fueron los sindicalistas ácratas (Basadre, Ibid) 
posibilidad real, era objeto de discusión y motivo de conciencia y movilización para un gran sector del proletariado urbano que, dejando su vida provinciana campesina, llegaba a las ciudades de la costa para engrosar las filas de obreros. ${ }^{11}$

Cabe agregar, que un siglo después, en pleno siglo XXI, la concepción ácrata sigue vigente y recupera presencia. Por eso es relevante el pensamiento ácrata del lingüista Noam Chomsky, representante contemporáneo del anarco-sindicalismo, el tomarlo como objeto de estudio, enfocándose en su concepto de libertad, el cual nos coloca en el ámbito de la discusión ética y de la filosofía de la historia.

Como en el caso de González Prada, Manuel y Delfín Lévano, padre e hijo, manifestaban su escepticismo respecto de la política oficial. Era, pues, el discurso ácrata, centrado en el problema socioeconómico de fondo; más allá de las abstracciones creadas por la política institucional, se trataba de la revolución que confrontaría al pueblo con su propio destino. Si tal revolución mundial no se dio, entre otras razones fue por la consolidación económica, política y militar del modelo capitalista; $y$, por otro lado, por el establecimiento del Estado soviético en Rusia. ${ }^{12}$

Este viraje de la historia, debilitó la actividad del movimiento ácrata, a nivel global y redujo el anarco-sindicalismo a un activismo, basado en las huelgas que rápidamente eran compensadas en el mundo capitalista, por la sofisticación de las condiciones de vida de la clase trabajadora (Foucault, 1978-1979), (en el caso de Europa occidental y Estados Unidos), la implantación de férreas dictaduras (Rouquie, 1981) (en América Latina) y en todo caso, convirtió el debate ácrata, en una discusión propia de estudiantes e intelectuales (Breton, 1924). De ahí, la importancia, sostengo, de la obra de Noam Chomsky; entre otros, quienes sostienen la vigencia del discurso y la actitud ácrata, en el mundo contemporáneo.

\subsection{Acercamiento teórico al pensamiento de Manuel y Delfín Lévano}

¿Y cuando los pueblos se desengañen que, después de cuatro años de estarse destrozando, lo único que han conseguido vencido y vencedor, es más hambre y miseria? Y que por más huelgas que hagan, siempre serán las víctimas de los privilegiados capitalistas y gobernantes. ¿A quién volverán los ojos? ¿Hacia dónde dirigirán sus pasos?... (...) ¡Yo creo, pues, que los convencidos de estas verdades, en estos momentos de prueba, debemos ser sinceros con el obrero que sufre, que es nuestro hermano! ¡Es entre el pueblo, la única morada en la cual los Anarquistas Comu-

11 La viabilidad de la opción ácrata se debilitó, años más tarde, por el triunfo de la revolución bolchevique leninista en Rusia, en 1917. Más, el tiempo le daría la razón a la crítica ácrata: León Trotsky, fundador del ejército rojo, se vio obligado a partir al exilio, siendo asesinado por un stalinista en México, en 1940. Con Josef Stalin se dio el paso a la burocratización del régimen soviético y la cancelación de toda utopía, con su doctrina del "Socialismo en un solo país".

12 Esto ilusionó a muchos miembros de la clase trabajadora, que dejaron su compromiso ácrata adhiriéndose a la militancia política marxista o la socialdemocracia (representadas en el Perú por José Carlos Mariátegui, fundador del Partido Socialista y por Víctor Raúl Haya de la Torre, fundador del APRA, respectivamente). 
nistas debemos actuar, porque es nuestra propia casa! (...) Necesitamos hacernos entender, explicar la causa de los males sociales y el único medio para conjurarlos; la revolución hecha por los trabajadores, por todas las víctimas del régimen burgués; ¡no para matar hombres, sino para destruir todos los privilegios!” ¡Anarquistas, comunistas, siempre!

Lévano, Manuel y Delfín (2006).

Manuel y Delfín Lévano destacan como representantes del discurso ácrata en el Perú del siglo XX. Su praxis anarco-sindicalista, los define históricamente. ¿Cuál es la relevancia concreta de dicho discurso para la historia cultural del Perú? ¿Por qué me permito comenzar una explicación sobre el concepto de libertad de un autor norteamericano - a nivel filosófico y desde un enfoque analítico-hermenéutico- citando autores peruanos, ubicados en otro contexto espacio-temporal? Hago esta exposición porque afirmo el valor, específicamente, meta-textual del discurso ácrata. Más allá de contingencias momentáneas, la acracia se afirma como discurso fundado en valores universales que las herramientas de la crítica permiten reconocer. Esta ciertamente, es una cuestión de opción. ${ }^{13}$

El valor de la acracia sea en 1919 o cien años después, está vigente. El sistema capitalista se halla en profunda crisis, sostenido por su convencionalidad: las desigualdades son más evidentes. Se requiere de puntos de vista cuestionadores, el mundo entero en su complejidad podría funcionar mejor y la acracia aportaría soluciones objetivas a los graves problemas; sea en los niveles de las prácticas sociales como del discursivo de la teoría y la argumentación.

\subsection{Contexto cultural del pensamiento de Manuel y Delfín Lévano}

El ideal anárquico. Pero nuestro ideal es otro. No es aniquilamiento sino construcción armónica, no es odio sino amor. Doctrina integral de la vida, en las relaciones individuales o colectivas, en el orden social, político, moral y económico tiene soluciones fijas, tendencias definidas. Antiestatal en Política, comunista en Economía, pacifista en el orden internacional, preconizador de la solidaridad igualitaria en el orden social y del reinado de la naturaleza y de la satisfacción de las necesidades en el moral, el ideal anárquico amplio y grandioso busca la extirpación de las supervivencias del instinto bárbaro y salvaje, la abolición de instituciones basadas en la coacción brutal de la fuerza, el restablecimiento por la igualdad del equilibrio social, la oposición a las desviaciones y degeneraciones de los sentimientos naturales engendrados por los prejuicios y los intereses y apoyado por los principios irrefutables de la ciencia e impulsado por las deficiencias de la realidad (...) y elaborando un mundo nuevo en donde en amplia y generosa comunidad se habrá garantizado a todos estos dos principios fundamentales, estas dos

13 Personalmente, me defino como ácrata, tengo conciencia de mi origen proletario, andino, sudamericano, heterosexual, etc., y esto me permite reconocerme en un punto de vista que va más allá de las barreras y limitaciones que nos impone el modelo hegemónico global. 
necesidades imprescindibles e inalienables y desconocidas hoy: la vida y la libertad.

(...) Ese es nuestro grandioso ideal. ¡Esa es la sublime Anarquía!

$$
\text { Cf: Lévano, Manuel y Delfín (2006). }
$$

En un contexto histórico como el descrito ¿En qué consiste la acracia? ¿Cuál es su problematicidad? Es una situación de libertad, un reino dónde la moralidad y la justicia se hacen presentes. Allí no existe el protagonismo, el liderazgo, la aplastante jerarquía, etc.: existe la solidaridad, la amistad, la confianza. La satisfacción por participar en la creación de un mundo nuevo con una nueva historia. El imperativo categórico vigente es la necesidad de la independencia; es por ello que no bastó con que América Latina se liberase de la corona española. Hizo falta entregar la tierra, el trabajo y la riqueza producida a sus legítimos propietarios. Fue necesaria la superación de las barreras culturales que legitimaban las desigualdades como el "espíritu de casta y abolengo", el racismo y el sometimiento del género femenino, entre otros problemas. Estas carencias por diversas razones no se dieron.

Se puede argumentar la existencia de una necesaria relación entre moralidad, historia y acracia: el ser humano está dotado de una autoconciencia que le permite actuar de modo vital; por esta razón, se ve en la necesidad de vivir en comunidad (Biehl-Bookchin, 2009), de modo organizado y reflexivo, porque la acracia es legítima anti-política, si entendemos la noción de política tal como se plantea en la Modernidad occidental, a partir de Nicolás Maquiavelo (1531/1984).

No es casualidad, en el ámbito ácrata estadounidense, contra lo que el mismo Chomsky afirma, que en su obra se dé simultáneamente un interés por la acracia y un trabajo profesional centrado en el discurso cartesiano, entendiendo la creatividad del lenguaje humano como una manifestación innata y sinónima de la libertad. (Lorenzo, 2001). Es verdad, entonces, que a) El problema del sentido de la libertad, desborda la discusión ideológica; b) Es un problema ético con relevancia concreta, le afecta tanto al campesino como al obrero o al catedrático o al pescador; c) La libertad es inseparable de la definición universal del ser humano. Es la praxis auténtica de su ser consciente.

La experiencia humana como tal es diversa, pero es susceptible de ser definida de modo lógico-lingüístico y así, ser comprendida racionalmente.

\subsection{Relevancia del pensamiento de Manuel y Delfín Lévano}

De modo preliminar, tenemos señaladas las propiedades de nuestro objeto de estudio: tanto en Manuel González Prada como en Manuel y Delfín Lévano, reconocemos un llamado a la revolución, al auténtico cambio social, económico y cultural. En tanto ácrata, este discurso es compartido por la reflexión anárquica de Noam Chomsky. Ahora bien, suponemos que dada la rigurosa formación científica del lingüista norteamericano este afirma, con la sobriedad que lo caracteriza, si bien se 
parte de principios universales, será la contrastación con las condiciones objetivas lo que legitimará la propuesta ácrata. O sea, no hay un modelo algorítmico, mecánico, de puesta en práctica de la teoría libertaria; serán las sociedades, los consensos, los que libremente elijan participar de dicho paradigma teórico-ético-social.

Como se mencionó, existen pocos ejemplos puntuales de acracia: Cataluña y Aragón, en la España antifranquista de 1937 (Gayubas, 2012) y los kibbutzim israelíes (Kibbutz Program Center, 2012) que aún subsisten como modelo colectivo, integrados al Estado israelí. A ello habría que agregar las subculturas urbanas que se dan en Europa, Norteamérica o Latinoamérica y que se reclaman de raíces libertarias, como los Punk ingleses o los Okupas españoles de las décadas de 1980 y 1990 que sobreviven diversificados en la pluralidad de subculturas estéticas, eróticas, mass-mediáticas, etc., que se dan en la actualidad.

Como señalan Manuel y Delfín Lévano, la acracia es un ideal y como tal es una creación espiritual que manifiesta toda una concepción del mundo. Si bien deja de ocuparse de problemas tales como la existencia de un determinado Dios o la validez de cierta religión, aborda aspectos de la vida que se experimentan en el diario devenir pero que no por ello son irrelevantes o anodinos. De hecho, el trabajo, los recursos materiales tales como la vivienda, la alimentación, la salud, la formación integral mediante el estudio, la coexistencia social, la conservación del ecosistema, etc., son necesidades tangibles, reales y compartidas por todos los seres humanos.

Como ácratas convencidos Manuel y Delfín Lévano, sustentan la postura libertaria respecto de las relaciones individuales o colectivas, sea en el orden social, político, moral o económico. Para ellos, como para el surrealista francés André Breton (1993), primero está la vida.

En ello nos apoyamos para deslindar de toda mala interpretación del discurso o actitud ácratas, pretendiendo relacionarlo con formas deshumanizadas de subversión. Dichas posturas se auto descalifican como ácratas en la medida que, al introducir modos de organización basados en la jerarquía y disciplina, propiamente castrenses y represivos, invalidan toda legítima aspiración libertaria.

\section{La doctrina de la libertad en el pensamiento de Noam Chomsky}

Habiendo introducido el tema ácrata con autores de la tradición libertaria peruana, se pasa a la discusión estrictamente filosófica, a la calidad de la argumentación, a la sustentabilidad de lo que se afirma. Es decir, se pasa del libre pensamiento a la especulación académica, no por ello más o, menos interesante, pero si ubicada en una dimensión distinta que no cancela la crítica, sino más bien permite su reelaboración y perfectibilidad.

Supóngase, haciendo ejercicio de la imaginación, que se viviese en un mundo sometido a regularidades estrictas — más de lo que son en la cotidiana realidad 
concreta - que fuese imposible y con ello, impensable la posibilidad de introducir modificaciones. ¡Este mundo no estaría hecho para ser habitado por seres humanos! $\mathrm{Y}$ esto porque, el sentido de humanidad implica necesariamente azar, discontinuidad, dinamismo, autocorrección, retroalimentación, etc. Con este argumento último se desbarata este experimento mental. Para que exista noción de historia, tiene que haber noción de cambios. Pues bien, esto lleva, a adelantar la defensa de la hipótesis central del presente estudio, cual es, el sentido de la libertad en la obra de Noam Chomsky.

La condición de libertad es inherente a la vida humana. Si bien, a nivel de ideas, existen estructuras fijas, precisamente paradigmáticas, en el mundo concreto de la vida social, en nombre de la defensa de dichas categorías conceptuales y axiológicas, se actúa eligiendo constantemente y esto ya es reconocimiento de dinámicas y rupturas. Puede concluirse, por ahora, que no hay tal incongruencia entre el desarrollo de los hechos en el mundo, el conocimiento metódico que se tiene de éste y la reflexión que genera.

\subsection{Acercamiento teórico al pensamiento de Noam Chomsky}

El anarquismo no es un sistema social fijo, hermético, sino una tendencia manifiesta en la evolución histórica de la humanidad, que, a diferencia de la tutela intelectual que ejercen las instituciones eclesiásticas o gubernamentales, aspira al desarrollo libre y expedito de todas las fuerzas individuales y sociales del hombre. $\mathrm{Ni}$ siquiera la libertad es un concepto absoluto, es sólo relativo, pues tiende a expandirse sin cesar y a alcanzar ámbitos cada vez más amplios de las formas más diversas. Para el anarquista, la libertad no es un concepto filosófico abstracto, sino la posibilidad concreta y fundamental que tiene cada ser humano de desarrollar plenamente las facultades, capacidades y talentos que le concede la naturaleza y ponerlos al servicio de la sociedad." (...) "Cuanto menos interfiera en este desarrollo natural del hombre el control eclesiástico o político, tanto más eficaz y armoniosa llegará a ser la personalidad humana y mejor muestra dará de la cultura intelectual que la ha engendrado."

Rocker, Rudolf citado por Chomsky, Noam (2015).

El problema peculiar de la historia como disciplina, radica en que se ocupa de hechos realizados por seres conscientes, lo cual no impide que a veces dichos seres tomen decisiones arbitrarias que conduzcan al desastre. Algo diferente ocurre con la filosofía que se ocupa del aspecto formal de lo existente. Podría preguntarse: ¿Existen puntos en común entre ambos niveles de la realidad? Y la respuesta sería afirmativa, pues aún la idea más abstracta y pura, es pensada por una conciencia humana, elaborada en un cerebro definido. Esto permite que la filosofía especule sobre la historia, pues esta es el conjunto universal de los hechos humanos, vale decir, sociales. 
Esto trae las siguientes consecuencias: si la historia es el desarrollo diacrónico de los hechos colectivos reflexionados y la filosofía es el ejercicio de dicha reflexión; esto obligará a que dicha filosofía reposa en bases científicas sólidas que le permiten brindar coherencia a sus postulados. Esto implicaría alejarse de dogmatismos y apariencias. Y esto conduciría a reflexionar sustentando una concepción del mundo que pueda articular coherentemente dichas informaciones y reflexiones. Con ello concluyo, en la medida que me lo permiten los argumentos presentados hasta el momento, que el discurso ácrata, sino es el único ni el mejor, por lo menos destaca entre los más indicados corpus teóricos que permiten una reflexión gnoseológica sana e inteligible.

\subsection{Contexto cultural del pensamiento de Noam Chomsky}

Cabría preguntarse qué interés puede tener el estudio de «una tendencia manifiesta en la evolución histórica de la humanidad» en el que no encuentra expresión ninguna teoría social concreta y pormenorizada. En efecto, muchos comentaristas desdeñan el anarquismo, calificándolo de ideal utópico, informe, primitivo y, en todo caso, incompatible con las realidades de una sociedad compleja. Sin embargo, nada impide adoptar una perspectiva muy distinta y afirmar que, en cada estadio de la historia, nuestro propósito debería ser erradicar aquellas formas de autoridad y opresión originarias que si bien en su momento pudieron tener una justificación por motivos de seguridad, supervivencia o desarrollo económico, en la actualidad agudizan la miseria material y cultural en lugar de contribuir a paliarla." (...) Desde este punto de vista, no hay ninguna doctrina del cambio social fija, válida para el presente y el futuro, como tampoco existe necesariamente una idea concreta e inalterable de las metas hacia las que debería tender el cambio social. Nuestra comprensión de la naturaleza humana y de la variedad de formas viables de sociedad es sin duda tan rudimentaria que cualquier doctrina con pretensiones universales debe contemplarse con el mayor escepticismo, del mismo modo que deberíamos desconfiar cada vez que oigamos que la "naturaleza humana" o "los imperativos de la eficiencia" o "la complejidad de la vida moderna" requieren tal o cual forma de opresión o autocracia."

Chomsky, Noam, (2015).

Como afirma Noam Chomsky, y esto es sumamente interesante, la libertad no es un concepto filosófico abstracto sino la posibilidad concreta de desarrollar en toda su potencialidad, las riquezas que posee la vida humana. De ello se puede inferir, las razones de la rebeldía permanente de los libertarios; rebeldía frente a todo lo que signifique opresión, abuso y desigualdad. Ciertamente, el contexto social en que se piensa la acracia, es el del mundo industrializado y desarrollado en el que éste se ubica: o sea, el problema no es el desarrollo ni la tecnología, como elementos negativos per se. De lo que se trata es de aprovechar de la manera más productiva y sana, todas las posibilidades que brinda el progreso humano para avanzar en la historia hacia un futuro, pleno de sentido y significación. 
Me parece notable la cerrada defensa que hace Noam Chomsky: nótese que responde a cada crítica posible que se le hace al discurso ácrata, sobre todo a las acusaciones de "utópico", "informe" y "primitivo". El problema no radica en las propuestas libertarias sino, más bien, en las desgastadas formas de organizar la sociedad, que ya no responden de modo productivo a las necesidades del colectivo humano y que por ello deben ser, necesariamente superadas. Es una cuestión de puntos de vista: quienes ejercen, arbitrariamente, el poder, previsiblemente han de defender aquello que le han arrebatado al conjunto de la humanidad, mientras que, del lado contrario, aquellos que han sido las víctimas de la historia - entendida como conjunto de hechos y además como la narración objetiva de los mismos-, necesariamente habrán de manifestar su inconformismo.

\subsection{Relevancia del pensamiento de Noam Chomsky}

Como se observa, Noam Chomsky es un intelectual posicionado en el mundo académico y lo que le confiere más valor a su propuesta es que no teme la cercanía de los desheredados, de los "pobres del mundo" ${ }^{14} \mathrm{He}$ ahí la mayor demostración de su humanismo. El libre compromiso, la libre elección, la libre decisión llevada a sus consecuencias más radicales. Esta es la auténtica crítica del sistema, la superación de los valores reaccionarios, negativos, fúnebres en su solemnidad de infierno.

Afortunadamente, la acracia no requiere de un edicto o de una "toma del poder" para ser puesta en práctica. En la familia, en la pareja, en el estudio, en el trabajo, entre los amigos y compañeros; cotidianamente, ahí se pueden poner en práctica los valores libertarios. Desde luego, pasarán generaciones para que se dé la utopía; se sabe y se asume; más ello no desmerece el esfuerzo de todos aquellos a lo largo y ancho del mundo: obreros, campesinos, milicianos, estudiantes, mujeres, hombres, compañeros todos que dieron su vida por un ideal de justicia, libertad y dignidad. He aquí una primera coincidencia a señalar, entre la actitud y el pensamiento de los autores revisados: Manuel González Prada, Manuel y Delfín Lévano y Noam Chomsky.

\section{A modo de conclusión preliminar}

Por lo visto, el pensamiento ácrata es digno de ser considerado filosofía o en todo caso, cosmovisión con implicancias ontológicas, axiológicas, éticas, gnoseológicas, etc.

Si bien muchos de sus exponentes fueron como Manuel y Delfín Lévano, obreros y jornaleros que dedicaban las horas de su descanso a la formulación teórica, han existido otros como Piotr Kropotkin o Manuel González Prada que, habiendo nacido entre los privilegiados sociales, se comprometieron con la causa de la libertad.

14 Verso de la" Internacional anarquista” 
En el caso de Noam Chomsky, estamos ante un intelectual que se ha ganado el respeto y la admiración de hombres y mujeres, maduros y jóvenes, a lo largo y extenso del mundo.

Y he aquí el valor del discurso ácrata: no es el nacimiento u origen de las personas lo que determina su pertenencia a determinada clase, cual, si se tratase de una casta indoeuropea medieval, es la libertad de conciencia la que dadas ciertas condiciones favorables permite elegir y optar por determinados principios de vida, rompiendo con fatalismos deterministas. Y esta libertad de elección es definitivamente compatible con el altruista valor libertario de la solidaridad. Solidaridad responsable de y con la humanidad.

\section{Referencias}

Bakunin, M. (2002). Dios y el Estado. Madrid. Confederación Nacional del Trabajo. [19/1/2017] Recuperado de: http://metalmadrid.cnt.es/cultura/libros/mijail-bakunin-dios-y-el-estado.pdf

Basadre Grohmann, J. (1998). Historia de la República del Perú. Lima: Diario “La República". $8^{\circ}$ ed. Universidad Ricardo Palma.

Biblioteca Nacional de Chile. (2016). Diego Portales Palazuelos. (1793-1837) Arquitecto de la República Autoritaria. [20/01/2017- 04: 08 a.m] Recuperado de: http:// www.memoriachilena.cl/602/w3-article-3358.html

Biehl, Janet-Bookchin, Murray. (2009). Las politicas de la ecología social, Barcelona. $2^{\circ}$ edición. Lallevir S.L./Virus Editorial. [19/01/2017- 07:42 p.m] Recuperado de: http://www.enxarxa.com/biblioteca/BIEHL\%20Municipalismo\%20libertario.pdf

Breton, André. (1993). Poemas. Lima. Jaime Campodónico Editor.

Chomsky, Noam. (2015). Razones para la anarquia, Malpaso, [20/01/2017-12:01 pm] Recuperado de: http:/www.elboomeran.com/upload/ficheros/obras/adelanto_razones_para_la_anarquia.pdf

Gayubas, Augusto. [2012]. La experiencia anarquista. Colectivizaciones en España 1936/1937. [19/01/2017-08: 15 p.m] Recuperado de: http://sagunto. cnt.es/wp-content/uploads/2010/12/LA-EXPERIENCIA-ANARQUISTA-COLECTIVIZACIONES-EN-ESPA\%C3\%91A-1936-1937.pdf. http://www.portaloaca.com/historia/revolucion-social/9869-la-experiencia-anarquista-colectivizaciones-en-espana-1936-1937.html

González Prada, Manuel. (2010). jLos jóvenes a la obra! Textos esenciales. Estudio preliminar, selección y notas: David Sobrevilla. Lima. Fondo editorial del Congreso del Perú.

Kibbutz Program Center. (2012). New York, [20/01/2017- 03:00 a.m]. Recuperado de: http://www.kibbutzprogramcenter.org 
Kropotkin, Piotr Alexeievich. [1922] (2012a). Origen y evolución de la moral, Buenos Aires, América lee, [20/01/2016- 03:02 a.m]. Recuperado de: https:// materialesfopep.files.wordpress.com/2012/04/kropotkin-origen-y-evolucic3b3n-de-la-moral.pdf)

Lévano, Manuel y Delfín. (2006). La utopia libertaria en el Perú. Obra completa, Compilación: César Lévano y Luis Tejada. Lima. Fondo Editorial del Congreso del Perú

Loach, Ken (director). (1995). Tierra y libertad (película). Reino Unido, Italia, España, Alemania. British Broadcasting Corporation (BBC), Poly Gram Filmed Entertainment, British Screen Productions, Eurimages, Messidor Films S.L., Working Title Films, Degeto Film, Road Movies DritteProduktionen, BIM, Filmstiftung Nordrhein-Westfalen, European Co-production Fund, Diaphana Films, Televisión Española (TVE), Canal+ España, Parallax Pictures (Productores) [20/01/2017- 03:19]. Recuperado de:http://cine.estamosrodando.com/ peliculas/tierra-y-libertad/ficha-tecnica-ampliada a.m.)

Lorenzo, Anselmo. (1913). Contra la ignorancia, [30/01/2017- 11:02 a.m.] Recuperado de: http://www.anselmolorenzo.es/publicaciones/publi/Anselmo\%20 Lorenzo\%20-Contra\%201a\%20ignorancia.pdf

Lorenzo Gonzales, Guillermo. (2001). Comprender a Chomsky. Madrid. Machado Libros.

Maquiavelo, Nicolás. (1983). El príncipe, Madrid, Sarpe.

Marx, C. [1859] (2001). Prólogo a la contribución de la crítica de la economía política. Marxist Internet Archive, [20/01//2017- 03:32 a.m]. Recuperado de: https:// www.marxists.org/espanol/m-e/1850s/criteconpol.htm

Marx, Karl-Engels, Friedrich. [1848] (2011). Manifiesto del Partido Comunista. Centro de Estudios Socialistas Carlos Marx. México. [20/01/2017-03:28 a.m]. Recuperado de: http://centromarx.org/images/stories/PDF/manifiesto\%20comunista.pdf

Rouquie, Alain. 1981. Dictaduras, Militares y Legitimidad en América latina: [20/01/2017-02:11 p.m]. Recuperado de: http://bibliotecavirtual.clacso.org. ar/ar/libros/critica/nro5/ROUQUIE.pdf

Confederación General del Trabajo. 2011. Internacional anarquista (versión española, archivo de audio y video). [19/01/2017-11:00 p.m]. http://cgt.org.es. Recuperado de: (http://liberarlasmentes.blogspot.pe/ 